\title{
RELATOS DE VIOLENCIA Y MUERTE INDÍGENA EN LA FRONTERA ANDINA DEL NORTE DE CHILE (SIGLO XX)*
}

\author{
RECORDS OF VIOLENCE AND INDIGENOUS DEATH IN THE \\ ANDEAN BORDER IN THE NORTH OF CHILE (XX CENTURY)
}

\author{
Hans Gundermann Kroll ${ }^{* *}$, Jorge Iván Vergara del Solar ${ }^{* * *}$ y Héctor González Cortés****
}

A la memoria de don Leonardo Reyes, un atacameño particular

\begin{abstract}
La coacción física de agentes estatales (policía, autoridades locales, funcionarios públicos, integrantes del ejército) hacia los indígenas en el norte de Chile tiene características propias si se la compara con la resistencia mapuche en la defensa de la tierra desde fines del siglo XIX hasta el término de la dictadura. En ambos casos es común que surja con ocasión de tensiones y conflictos entre particulares (hacendados y especuladores de tierras con indígenas; entre familias y comunidades indígenas; entre campesinos indígenas y no indígenas). Pero en las regiones andinas del norte del país se trata de áreas marginales de altura donde la presencia del Estado es, salvo momentos especiales, recurrentemente débil, a diferencia de la temprana formación del Estado (y de una región agraria) en La Araucanía. Adquieren importancia, en cambio, el control de fronteras (con Bolivia, Argentina y Perú) y la imposición-disputa por la nacionalidad de la población de regiones anexadas por la Guerra del Pacífico. Presentamos algunos casos en que la violencia de funcionarios públicos (policías, integrantes de las fuerzas armadas y funcionarios) se dirige a indígenas del espacio andino, sea que ello irrumpa en conflictos locales, o es el resultado de acción sin control (abuso de poder, represión) de agentes estatales. A veces de manera combinada. En los casos presentados la violencia y muerte se acompaña de percepciones de extranjeridad, primitivismo e impunidad y, desde el lado indígena, como actos de arbitrariedad y sentimientos de impotencia.

Palabras claves: Violencia física, agentes estatales, indígenas, fronteras, norte de Chile.
\end{abstract}

The physical coercion of state agents (police, local authorities, public officials, members of the army) towards the indigenous people in northern Chile has its own characteristics when compared to the Mapuche resistance in the defense of the land from the end of the 19th century until the term of the dictatorship. In both cases, it is common that it arises on the occasion of tensions and conflicts between individuals (landowners and speculators of lands with indigenous people, between families and indigenous communities, between indigenous and non-indigenous peasants). However, in the Andean regions of the north of the country they are marginal areas of height where the presence of the State is, except for special moments, recurrently weak, unlike the early formation of the State (and of an agrarian region) in Araucanía. On the other hand, the control of borders (with Bolivia, Argentina and Peru) and the imposition-dispute for the nationality of the population of regions annexed by the War of the Pacific acquire importance. We present some cases in which the violence of public officials (police, members of the armed forces and civil servants) is directed at indigenous people of the Andean space, whether it breaks into local conflicts, or is the result of uncontrolled action (abuse of power, repression) of state agents. Sometimes in a combined way. In the cases presented, violence and death are accompanied by perceptions of strangeness, primitivism and impunity and, from the indigenous side, as acts of arbitrariness and feelings of helplessness.

Key words: Physical violence, state agents, indigenous, borders, northern Chile.

\section{El norte de Chile, Estado, minería y espacio andino}

La anexión y dominio de las regiones del norte de Chile se hizo a expensas de sus países vecinos Perú y Bolivia, como resultado de una guerra por el control de riquezas minerales y de negociaciones ulteriores, entre fines del siglo XIX y primeras décadas del siglo XX. El foco de interés económico extractivo se encontraba en el desierto intermedio, los puertos de la costa del Pacífico y las vías de comunicación y transporte que conectaban

\footnotetext{
* Resultado Proyectos Fondecyt Regular No 1140573 y No 150573.

** Universidad Católica del Norte, Instituto de Arqueología y Antropología, San Pedro de Atacama, Chile. Correo electrónico: hgunder@ucn.cl

*** Universidad de Concepción, Departamento de Antropología, Concepción, Chile. Correo electrónico: jivanvergara@ gmail.com *****Universidad de Tarapacá, Departamento de Antropología, Arica. Chile. Correo electrónico: hgonzale@uta.cl
} 
distritos mineros con los puertos de embarque. De hecho, la conformación de una estructura regional de centros urbanos, áreas de actividad económica y transporte así como la conocemos hoy se explica en buena medida por los ciclos extractivos modernos: el ciclo salitrero en su fase expansiva y de ulterior crisis, entre 1890-1930; la minería mixta con predominio del cobre en la década de 1940 hasta la de 1980, en particular con la operación de la mina Chuquicamata; y, por último, el expansivo ciclo extractivo neoliberal que se vivió desde fines de la década de 1980. La minería metálica y de sales en la precordillera y cordillera andina ha estado presente en todos los ciclos, sin representar el componente principal de cada uno de ellos, con la excepción de Chuquicamata a 2870 m.s.n.m. respecto del período 1940-1980, lapso en que languidecía la minería en la cordillera de la Costa y la depresión intermedia. En aquellos casos en que se desarrollaron minerías de altura (azufre en Tacora, azufreras de la zona de San Pedro de Atacama y en la actual comuna de Ollagüe; bórax en Surire y Ascotán; oro y plata en Choquelimpie; oro y plata en Collahuasi) un factor crítico fue su dependencia de los ferrocarriles (Arica-La Paz y Antofagasta Bolivia) o sistemas combinados en que el ferrocarril fue indispensable. Desde temprano se verifica, también, el empleo de camiones (Richard et al., 2016: 89-111).

Las fronteras nacionales transcurren por regiones altoandinas (salvo una pequeña área septentrional con Perú que llega al Pacífico entre las ciudades de Arica y Tacna) en alturas que transcurren alrededor de los 4.000 m.s.n.m., en una extensión de alrededor de $1.500 \mathrm{~km}$ de norte a sur. Esas fronteras en parte corresponden a divisiones coloniales (Alto y Bajo Perú; divisiones de provincias coloniales) o son el resultado de definiciones modernas resultantes de la Guerra del Pacífico y acuerdos territoriales derivados (tratado de límites con Perú de 1883 y 1929; definición de límites con Argentina en la Puna de Atacama de 1899; tratado con Bolivia de 1904). Junto con lo anterior, el interés chileno de contar con territorios de "seguridad" en el norte anexado formó parte de la definición de fronteras (caso de Arica con Perú; y la propia cordillera de los Andes por el lado oriental, a fines del siglo XIX todavía una barrera geográfica formidable para las comunicaciones, el transporte y la acción militar).

Las áreas de frontera andinas estaban y están habitadas por poblaciones indígenas, culturalmente aymara, quechua, atacameño y colla. Todas con filiaciones histórico-culturales (lingüísticas y culturales) andinas, aunque no todas presentes en estos territorios desde tiempos coloniales. Collas y quechuas arriban a la zona desde Bolivia y noroeste de Argentina, respectivamente, ya desde fines del siglo XIX, atraídos por posibilidades de trabajo y conexión a mercados de productos agropecuarios que el dinamismo minero abrió en toda la región norte (ciclo salitrero, la explotación cuprífera de Chuquicamata, la extracción de bórax y azufre, la explotación de yareteras y queñuales). Cuando la definición de fronteras se estableció sobre límites de jurisdicciones administrativas coloniales, localidades y comunidades indígenas mantuvieron en lo general las delimitaciones territoriales antiguas. Aunque, sobre ellas podrían preexistir conflictos que a veces se reactivaron y en otras ocasiones no, o precisamente se abren con ocasión de demarcaciones de frontera más precisas (Gundermann, 2001: 105-143, para el caso de Isluga; Castro, 2016: 113-144, para el de Isluga y Cariquima, ambas comunidades en los altos de Tarapacá). En otros casos, comunidades y grupos étnicos vieron divididos los territorios preexistentes. Es la situación vivida en el sector de Visviri con la comunidad aymara histórica Ancomarca en donde una parte quedó en Chile y otra en Perú (González H. y González S., 2018: 7-22). Lo es también la separación entre comunidades atacameñas de la Puna de Atacama con aquellas de los oasis y pie del desierto. Las primeras, Susques, Antofagasta de la Sierra y Catua, quedaron en Argentina con la definición por arbitraje de los límites en esa extensa región de altura. Las otras en Chile, actuales del área circundante al Salar de Atacama y a lo largo de la cuenca alta del río Loa.

A los indígenas de Tarapacá, Arica y Antofagasta se les aplicó las modalidades de gobierno, administración y legalidad generales. Se organizó un régimen administrativo estructurado en provincias o departamentos, subdelegaciones y distritos con cabeceras político-administrativas en los puertos de la costa, haciendo desaparecer o limitando funciones y atribuciones de autoridades indígenas cuando ellas todavía persistían. Para cada unidad administrativa se nombraban autoridades y funcionarios. Los distritos andinos normalmente contaron con personeros designados entre los vecinos considerados influyentes e ilustrados (Subdelegados, Inspectores de Distrito, Jueces de Distrito) (Díaz et al., 2004; Castro, 2008) ${ }^{1}$. Si bien ello se logró, 
con intermitencias, en los valles costeros y en los principales poblados de la precordillera andina, para los sectores más distantes y aislados esa condición fue mucho más difícil de alcanzar. Así también, en el profesorado de las escuelas públicas se vio agentes de inculcación de símbolos nacionales chilenos; otro tanto con la conscripción militar de los jóvenes varones. La salida de curas católicos peruanos y su reemplazo por sacerdotes de la vicaría castrense chilena cumplió una función ideológica similar (Tudela, 1992, 2002; González S., 2002; Díaz, 2006; Díaz y Ruz, 2009)².

Con la culminación de la minería del salitre en el desierto intermedio, la minería andina conoce de términos (extracción de bórax en Ascotán, plata y oro en Collahuasi), aperturas y ampliaciones (como la del cobre en Chuquicamata y, más adelante, un ciclo de extracción de azufre desde volcanes andinos en Arica y Antofagasta). Con la crisis salitrera la economía agropecuaria de los campesinos andinos deja de tener la demanda que conoció durante el ciclo expansivo de la minería regional (forrajes, ganado menor, chacarería) y la oferta de trabajo en las faenas extractivas disminuyó. Ello condujo a la retracción hacia economías menos mercantilizadas y, por otra, a emigraciones hacia los centros mineros subsistentes y los puertos nortinos (González, H. 1996; Gundermann, 2001: 273-338). Planes de desarrollo estatales tocaron las zonas andinas, en respuesta a la situación de crisis que padecía el norte del país. Favorecieron la apertura y mejoramiento de caminos y generaron actividad económica en las áreas intervenidas. El traslado de escuelas públicas cerradas en las oficinas y pueblos de la zona salitrera de Tarapacá resolvió la demanda de servicios escolares en la precordillera andina, primero, y en los valles altos y altiplano, después. La instalación de escuelas es incluso anterior a la crisis salitrera en la precordillera de Arica y Tarapacá. Hacia fines de la década de 1950 prácticamente todo el espacio andino quedó cubierto por una red de escuelas primarias que dieron impulso a la integración cultural, ideológica y lingüística de las poblaciones indígenas andinas (Gundermann et al., 2011).

Se asiste así a la expansión de las comunicaciones terrestres y a la instalación de servicios escolares y requerimientos de mayor seguridad y control en las fronteras. En todo esto tuvieron una muy activa contraparte las propias comunidades mediante una persistente demanda por desarrollo local.
Un destacado papel jugaron figuras organizativas como los "Comités de Adelanto" o "Juntas para el Progreso", basadas en asambleas y organizaciones locales e impulsadas por dirigentes, líderes y vecinos influyentes, particularmente motivados por sacar a sus comunidades del estado de postración, atraso, aislamiento y falta de progreso con que definían su situación. Acción que lleva a constatar la fuerza con que por ese entonces se habían incorporado objetivos de cambio social modernizador en donde una mayor presencia estatal en las regiones andinas era considerada indispensable.

Las décadas de 1960, 1970 y 1980 pueden caracterizarse como activamente desarrollistas y de integración de los espacios andinos a sus regiones, con una mayor presencia estatal y control de fronteras. Bajo el gobierno autoritario, esa integración y desarrollismo presenta una definida impronta geopolítica. La década de 1960 e inicios de la siguiente es, con variantes, la de gobiernos con proyectos de desarrollo, participación popular e integración territorial, de manera notoria mediante la acción de la Corporación de Fomento (CORFO) o el Plan Andino de la Junta de Adelanto de Arica, políticas como la de la Promoción Popular (gobierno de Frei, 1964-1970), o desarrollo local y ampliación de derechos sociales y políticos en las zonas interiores (gobierno de Allende, 1970-1973). Tiene lugar una mayor inversión pública en áreas críticas para la integración de las zonas interiores (vialidad, infraestructura de riego y drenaje, construcción y mejoramiento de escuelas), y el fomento de organizaciones de base de nuevo cuño alentado por la participación popular: Juntas de Vecinos, Centros de Madres y clubes deportivos.

Dando continuidad a un impulso inaugurado en la década de 1940 y 1950, se advierte una sostenida acción de construcción de caminos, conectando poblados y comunidades con enlaces ferroviarios, unidades urbanas del desierto y faenas mineras (ferrocarriles Arica-La Paz, o AntofagastaBolivia, la ciudad de Calama, el centro cuprífero de Chuquicamata) y las ciudades portuarias de la costa (Arica, Iquique, Antofagasta, Tocopilla). Infraestructura ferroviaria y de caminos son más antiguas pero estaban mal conectadas con los poblados y comunidades andinas, una situación que ahora se resuelve. A la persistente demanda por servicios educacionales, por esos años ya operando, se agregan otros servicios como aumentar dotaciones de policía en la frontera y los 
pueblos mayores, o los nombramientos de jueces e inspectores de distrito, la presencia de delegados municipales en algunos sitios importantes, o las campañas sanitarias y de ayuda social.

En relación con los años precedentes, el período dictatorial (1973-1989) presenta características propias. Una política no indígena y en algunos aspectos directamente antiindígena, una visión geopolítica de integración de regiones marginales y de reforzamiento de fronteras con políticas sensibles orienta la acción pública de esos años. La contingencia del centenario de la Guerra del Pacífico en la relación con Perú y Bolivia, y las serias tensiones políticas con Argentina en el llamado "Diferendo por el Beagle" explican en parte el enfoque mencionado. Lo anterior se complementa con una consistente voluntad política de integración territorial de regiones geográficas marginales, como el espacio andino del norte chileno. Integración que desde los poblados y comunidades andinas fue notoriamente bien recibida.

\section{Comunidades indígenas, espacios de frontera, control estatal y mercado}

Las poblaciones indígenas y mestizas de las áreas ubicadas a uno y otro lado de la cordillera de los Andes (altiplanicies, regiones puneñas, al oriente; valles y oasis al occidente) sostenían flujos económicos persistentes de intercambio complementario: productos y subproductos agrícolas de los valles y oasis intercambiados por productos y subproductos pecuarios de la cordillera y altiplanicies. En este sentido, aymaras, quechuas y atacameños han jugado un rol fundamental en el tráfico de bienes, ya que su estratégica ubicación en la cordillera andina les permite actuar como un elemento pivote que conecta las áreas orientales y occidentales de los Andes. Su base productiva agropecuaria les proveyó con animales para el transporte: las llamas, especialmente adaptadas a las difíciles condiciones de altura, además de mulas y burros para los mismos fines. El caravaneo con llamas cargueras, burros y mulas permitía una conexión estacional fluida entre ambas zonas, cruzando las fronteras entre países. Además, participaron activamente en los sistemas de arrieraje que conectaron los distintos espacios económicos de la macrorregión norte y todo el espacio surandino, hasta que se abrieron los caminos interiores, las rutas internacionales y aparecieron los vehículos motorizados. Los desplazamientos por las áreas interiores suponen un alto grado de conocimiento de la geografía y de las rutas. Pero, también, el desarrollo de relaciones sociales con habitantes de esos sitios, con los que pueden llegar a establecer, además, vínculos de amistad o parentesco real o ficticio (como compadrazgos), que les aseguraban acogida u hospitalidad, favores, la consecución de trabajo, bienes u objetos, tasas equilibradas de intercambio o buenos precios, según fuera el caso.

Durante la vigencia del ciclo salitrero, los campesinos indígenas de la región de Tarapacá, por ejemplo, bajaban hasta ciertos puntos de la precordillera a cambiar o vender animales a comerciantes que los llevaban a las oficinas salitreras de Tarapacá (Gundermann, 1986). Los agricultores de los valles de esa misma zona viajaban permanentemente también a estas mismas para vender sus productos agrícolas (González, S., 1991). Hasta hace algunas pocas décadas, todavía era común que grupos de aymaras se movilizaran con sus caravanas de llamas desde el altiplano chileno hacia los valles precordilleranos o viajaban a comunidades ubicadas en sectores bolivianos para intercambiar productos (Provoste, 1977; González, H., 1997). Otro tanto podría decirse, con características propias, para el caso quechua (en el área de Ollagüe), o el atacameño y coya más al sur (Alto Loa, comuna de San Pedro de Atacama, altos de Copiapó). Desde las tierras altas de Bolivia y la Puna de Atacama argentina también fue común hasta hace pocos años los viajes de intercambio de bienes y comercio con comunidades campesinas de la vertiente occidental de los Andes, poblados y faenas mineras en Chile (Molina, 2017).

Se puede decir que comercio fronterizo y contrabando chileno-boliviano en las fronteras ha existido casi desde el mismo momento de la creación de los límites entre estos países (Riviére, 1979 y 1982). Dos grandes factores condicionan su mayor o menor auge en décadas pasadas. Primero, la débil industrialización boliviana contribuía a que parte de sus necesidades internas debieran ser cubiertas con productos de importación. El aumento de las ganancias mediante la evasión del pago de los impuestos de internación incentiva hasta hoy su ingreso ilegal. Segundo, determinadas coyunturas permitían y permiten la oscilación de precios y una oferta diferenciada que benefician a uno u otro país. Con el Puerto Libre de Arica -y desde mediados de los años de 1970 con la creación de la Zona Franca 
de Iquique- se ha generado una oferta de productos extranjeros muy baratos para los mercados bolivianos. A la vez, al menos desde esos mismos años, el subsidio a los productos básicos en Bolivia y la distancia de los mercados distribuidores ubicados en Arica e Iquique, ha permitido el flujo de ciertos artículos (como azúcar, combustible, bebidas, carne, etc.) ${ }^{3}$. De esta manera, las condiciones estructurales de la economía boliviana y las diferencias coyunturales de precios entre los dos países han estimulado la amplificación del tráfico fronterizo, en condiciones de ilegalidad o semilegalidad ${ }^{4}$.

Un ejemplo del aprovechamiento de períodos que favorecen el comercio fronterizo es lo que aconteció en los primeros años del gobierno de la Unidad Popular, cuando los precios de los artículos chilenos fueron considerablemente más baratos. Aprovechando esta oportunidad, algunos aymaras llegaron incluso hasta Santiago en búsqueda de mercancías para vender a vecinos o comerciantes bolivianos, arriesgando la posibilidad de su detención, pero al mismo tiempo acuciados por la alta rentabilidad del negocio ${ }^{5}$.

En 1976 entró en funcionamiento la Zona Franca de Iquique (ZOFRI). Así como aconteció con el Puerto Libre de Arica, que perduró hasta comienzos de los años setenta, rápidamente se generó un activo comercio hacia Bolivia. Ahora, no obstante, la existencia de mayores resguardos policiales y aduaneros restringieron el contrabando, al menos a gran escala. De todos modos, ello no aseguraba y asegura que buena parte de las reexpediciones ingrese ilegalmente a Bolivia y que, incluso, algunos cargamentos retornen por pasos no habilitados a Chile. El incremento del comercio fronterizo de mercancías desde la ZOFRI hacia el vecino país creó una gran demanda por transporte, además de impulsar por acción estatal un notorio mejoramiento de los caminos interiores. Asociado a ello se abrieron facilidades de movilización colectiva entre el altiplano y el puerto de Iquique.

La apertura más o menos contemporánea, hacia los años sesenta, de las rutas interiores permitió que las comunidades fronterizas de ambos países también aprovecharan la oferta de productos de factura industrial, de acuerdo con las ventajas de precios que presentaran en uno u otro lado de la frontera. El aumento de esta demanda, especialmente incentivada tras la creación de la ZOFRI, estimuló la formación de ferias fronterizas autorizadas, por lo común de régimen quincenal, entre los años setenta y comienzos de los ochenta. Otro tanto en las zonas fronterizas de la Región de Antofagasta (por ejemplo, Ollagüe). Así, en los altos de Arica se crearon las ferias Tripartito (en Visviri, que reúne comunidades de Chile, Perú y Bolivia, todavía vigente) y Japu (en Guallatire, inactiva); en tanto que en el altiplano de Iquique las de Pisiga, muy activa hasta el presente, y Parajalla, inactiva. Aunque las autoridades municipales de la época estaban interesadas en estimular la oferta de productos agropecuarios regionales, este objetivo se desvirtuó rápidamente y pronto se agregaron artículos de procedencia industrial adquiridos en Iquique e, incluso, la llegada de comerciantes no indígenas (Gundermann, 1986) ${ }^{6}$. Una versión nueva es la Feria del Trueque que se desarrolla periódicamente en el espacio atacameño tripartito (provincia de Susques, San Pedro de Atacacama y Quetena), en su origen una iniciativa surgida de la organización y coordinación étnica transfronteriza que buscó revivir y retomar el intercambio complementario (Garcés y Maureira, 2018: 241 y siguientes), pero que, como era de esperar, se mercantiliza y adquiere dinámicas propias.

Estas ferias, especialmente las más alejadas de la posibilidad de control o supervisión de parte de autoridades y fuerzas policiales, han amparado también actividades de contrabando (como, por ejemplo, el retorno de mercaderías ZOFRI de reexpedición, la venta de combustible boliviano, etc.), lo que determinó el cierre de algunas (como la de Parajalla). Además, aparte de que son un punto importante de encuentro social para las comunidades fronterizas, a veces también son utilizadas por individuos de ambos lados para acordar actividades comerciales no autorizadas, contrabando lisa y llanamente o circulación de cocaína y derivados.

En suma, la complementariedad de las economías indígenas ubicadas en distintos niveles ecológicos de altura, y entre comarcas vecinas de países fronterizos, mantuvo su vigencia durante gran parte del siglo XX, hasta en tanto sus economías permanecieron solo parcialmente monetarizadas y con patrones de vida rural y consumo de productos generados en la misma zona andina. $\mathrm{Y}$ hasta en tanto el control de fronteras por las policías y agentes estatales de unos y otros países no se endureció hasta el grado de hacer de estas prácticas de intercambio una actividad demasiado riesgosa (decomisos, multas, encarcelamientos, prisión, 
apremios físicos). De manera paralela, por varias décadas en complementación con el intercambio y reemplazándolo progresivamente, se abre paso una economía fronteriza mercantilizada. De hecho, el intercambio complementario coexistió con relaciones de mercado y por efecto de ella sufrió transformaciones progresivas, combinando productos campesinos con compraventa de productos industriales y adoptando términos de relación propios de las relaciones de mercado. A su vez, el comercio fronterizo legal e ilegal y clandestino estuvo presente desde inicios del siglo XX. Por ejemplo, hoja de coca desde Bolivia, para el consumo por trabajadores indígenas y no indígenas en la minería del desierto de Atacama bajo dominio chileno. O la exportación de fibra de camélidos desde Arica, el comercio en la cordillera con fibra de vicuña, el traslado de licores y telas de la textil Bellavista Tomé a Bolivia, lo mismo que productos electrónicos cuando se desarrolla esta industria en la ciudad de Arica durante la década de 1960. Equivalentes, aunque posiblemente en una escala de operación y volumen de bienes más acotado si se lo compara con la región aymara, tienen lugar en la frontera chileno-argentina y del extremo sur poniente boliviano (provincia Sur Lípez en Bolivia; Ollagüe y la comuna de San Pedro de Atacama en Chile, los pueblos y comunidades de la Puna de Atacama en Jujuy, Salta y Catamarca $)^{7}$. En todos los casos con participación de indígenas en la interfase de frontera en la cordillera andina. Pulsaciones en la demanda internacional o el dinamismo regional generado por el Puerto Libre de Arica y la acción de la Junta de Adelanto de Arica (desde mediados de la década de 1950) mantuvieron activo el comercio fronterizo y de productos altoandinos (como la lana de camélidos domésticos, fibra de vicuña o pieles de chinchilla), con el concurso de arrieros e intermediarios indígenas ${ }^{8}$. Desde Chile hacia Bolivia se recuerda el comercio con telas, licores, artefactos eléctricos y electrónicos. Lo que llevó, como en otros momentos previos en que se establecen circuitos de comercio, a una mayor preocupación por el control policial de flujos de mercancías en esas áreas limítrofes. Si bien esos períodos atrajeron la atención de autoridades de unos y otros países en función de su regulación, es hasta la década de 1970 que el intercambio complementario no suscitó mayores problemas, entre otras razones por las dificultades de control en una geografía difícil.

\section{Relatos de violencia y muerte}

En lo que sigue presentamos tres relatos seleccionados, comprehensivos de violencia y muerte indígena en las fronteras andinas de Chile con Bolivia y Argentina, en los que hubo participación de agentes del Estado:

\section{a) "Hankocollo" y la muerte de AM}

La familia M de Hankocollo (el nombre es ficticio) fue conocida en la comunidad histórica de Isluga como gente "hanjata" (matadores de gentes, demonios). Lo fueron por la participación de un grupo de hermanos en el asesinato de una familia de pastores bolivianos y el robo de su ganado y carga en un apartado y solitario sendero de la cordillera andina, en el sendero que conducía desde el salar de Surire al valle de Codpa -actualmente los altos de Arica- allá por los años de 1940 (las fechas no son seguras). Para ello usaron carabinas, palos y piedras. Los enterraron intentando ocultar los cuerpos. Los parientes de esa familia los buscaron rastreando cuidadosamente las rutas por donde pudieron transitar, hasta encontrar sus cuerpos. Conocido el caso, planteada la denuncia, realizada la búsqueda de los inculpados y apresados sus hechores, solo uno de ellos se autoinculpó y cumplió una larga condena en varias cárceles del país. Este grupo de hermanos, por su residencia en la alta cordillera aledaña a las rutas "troperas" (senderos para llamas cargueras, burros y mulas) que unen la comunidad de Sabaya y Huachacaya en Bolivia, junto a la frontera con Chile, y los valles de la precordillera andina chilena (Chiapa, Camiña, Miñe-Miñe), desarrolló varios robos a arrieros que realizaban viajes de intercambio, lo que acrecentó su fama de malhechores. Aun cuando esos hechos fueron conocidos, no estuvo al alcance de los afectados bolivianos iniciar acciones judiciales o sus denuncias no tuvieron consecuencias. Por esas décadas los arrieros evitaron entonces transitar solos o en grupos muy pequeños. La comunidad de Isluga por medio de su asamblea comunal, la intervención de sus caciques, Inspector y Juez de Paz, generó un acta de expulsión de esa familia de la comunidad. Ello no se concretó en lo que a la propiedad de los pastizales de altura y la residencia allí se refiere, pero sí en cuanto al rechazo y ostracismo social que esa familia vivió en lo sucesivo. Esto alcanzó no solo a los implicados directos en el asesinato 
colectivo. En lo sucesivo, a todos ellos no se les aceptaba o al menos se les aislaba de cualquier acto comunitario ampliado (fiestas patronales, carnavales, asambleas colectivas $)^{9}$.

Uno de sus miembros, AM, décadas más tarde, a principios de los años de 1960 (no se pudo precisar fecha ${ }^{10}$ ), favoreció el matrimonio de una de sus hijas, reputadas como de gran atractivo, con un vecino, viudo y muy mayor (JM), propietario de un enorme pastizal y dueño de muchas llamas, alpacas y burros. El matrimonio se realizó y la convivencia en el matrimonio se mantuvo sin contratiempos hasta que el hijo de ese hombre inició una relación amorosa con su madrastra. De ello resultaron dos hijos. Los relatos señalan que la tensión en este triángulo amoroso fue creciendo al punto que la pareja de amantes decidió deshacerse del hombre mayor, titular de la propiedad pastoril y de sus codiciados rebaños. La excusa surgió de un accidente de la hija pequeña, quien sufrió graves quemaduras como resultado de caer al fuego del hogar mientras sus cuidadores estaban ausentes en labores de pastoreo. Esas quemaduras le ocasionaron la muerte. La madre acusó a su esposo anciano de haber atentado contra la hija de ambos por celos, matándola con golpes y el uso de un palo. La niña fue enterrada y la seriedad de los hechos denunciados llevó a una actuación diligente de Carabineros y a un procedimiento sumario del tribunal. El acusado JM fue capturado, preso y condenado por parricidio. La situación de la pareja de amantes parecía haberse encaminado convenientemente para ellos.

No obstante estar preso, el viudo se las arregló para contactar y comprometer ayuda de un hermano (FM) reputado como "tinterillo" o "abogado" (conocedor y práctico en gestiones judiciales y civiles), quien averiguó los pormenores y consiguió ayuda legal para reabrir el caso en el tribunal de Pisagua. La solicitud de reapertura estaba basada en que la menor no murió por golpes propinados por el anciano, sino que por la gravedad de las quemaduras sufridas en un accidente doméstico. La exhumación de la menor y un informe de una nueva causa de muerte condujeron a una interrogación detallada a la madre de la niña muerta, citada ahora al tribunal como sospechosa de infanticidio. Esta nueva circunstancia hacía de la madre la responsable de la muerte, por falta de cuidados de la menor, y no su anciano esposo. El resultado de esta enérgica interrogación fue una nueva confesión y versión de lo ocurrido, cambiando el infanticidio por accidente en el hogar con causa de muerte. La mujer, arrepentida y apremiada por la posibilidad de ser acusada de un cuasihomicidio, habría confesado, inculpando en todo momento a su amante por inducción a una calumnia criminal. Según los relatos, se deshizo en llanto, hizo ruegos de perdón a su esposo y sentidas promesas de recta conducta en lo sucesivo. El compromiso del anciano viudo de no iniciar acciones legales contra ella y aceptar recibirla de nuevo en su casa facilitó las cosas. Todo lo anterior permitió la liberación del anciano, la madre escapando de la cárcel y al hijo sujeto de persecución por la justicia y su búsqueda por la policía. Poco tiempo después el anciano falleció en la localidad precordillerana de Camiña, mientras buscaba recuperarse de su alicaída salud. No habría alcanzado a visitar de nuevo su estancia, propiedades y ganado en la alta cordillera. Según otra versión, pudo retornar a la estancia altiplánica y permanecer con su esposa unos meses hasta que su estado de salud desmejoró y lo llevó de vuelta a Camiña. Mientras, el hijo permanecía escondido en los cerros, en contacto con la esposa de su padre, su madrastra y amante.

Los testimonios señalan que varios intentos de captura del hijo fugitivo fracasaron. Apenas asomaba Carabineros en el sector era avisado por el padre de la mujer, residente en un lugar que le permitía observar con anticipación la llegada de mulares o vehículos motorizados con Carabineros. Para ello prendía fuego a matorrales y su humo, fácilmente advertido por el buscado, servía para que se escondiera convenientemente. Informada la policía de tales maniobras, en un patrullaje ulterior interrogaron a AM y este se negó a informar nada, señalando completa ignorancia del paradero de la persona perseguida. Hastiados de la situación, los policías amarraron a AM al carro policial y lo arrastraron por la extensa planicie ubicada a los pies del caserío, buscando quebrar su empecinamiento en no entregar información de la persona perseguida, hijo del esposo de su hija. Numerosas veces, sin resultados. Fue dado por muerto y dejado tirado en el campo. Muchas horas más tarde fue auxiliado por un familiar y trasladado a su casa. Aquí se mantuvo postrado en estado grave por varios días. Por la gravedad de las heridas fue trasladado a lomo de mula al valle de Camiña, donde podría obtener auxilio médico. Un par de días después de llegar falleció. 
La familia no inició acciones legales y tampoco se llevó a efecto una investigación. No obstante, estos hechos fueron ampliamente conocidos y comentados en la comunidad de Isluga. Parientes, autoridades comunitarias o la propia policía no hicieron nada. Por razones distintas. La etiquetación de "gentes malas", familia de "matadores de personas" recayó sobre la víctima, lo que deprimió una reacción comunitaria basada en un sentido de justicia reparatoria. Un acendrado temor a Carabineros fue otra de ellos, temiendo algún tipo de represalia pero también con la percepción que un juicio contra los policías no conduciría a nada. La violencia policial excesiva con causa de muerte a terceros quedó entonces impune, sin sumario, investigación o juicio. En vistas del complejo panorama, el temor ante nuevas acciones policiales de búsqueda del prófugo y su eliminación física, amén de una muy negativa y amenazante actitud de la comunidad, llevó a la pareja decidir irse de la zona. Un día cualquiera muy de madrugada tomaron todos los animales y se trasladaron hacia el norte, hasta las inmediaciones de Putre, donde arrendaron o entraron en tratos de mediería de animales con propietarios del sector. Según la otra versión presentada, estos últimos hechos ocurrieron mientras el anciano esposo todavía estaba en su casa, con salud deteriorada y todo. En ese lapso se produjo la sustracción de los animales y huida de la pareja de amantes. Allá en las tierras altas de Parinacota terminaron sus vidas sin volver a la heredad de los padres. El temor a la persecución policial y la presión social hicieron insostenible su situación y decidieron marcharse, abandonando al esposo y padre.

\section{b) De Cariquima, amistad revolucionaria mediante, a un paso por Pisagua, una larga estadía postgolpe en Lebu, Chilla y finalmente Calama}

Don Zenón E. es un hombre viejo, ya en el final de sus días según sus propias palabras. Ha tenido una vida azarosa. Hasta que fue adulto podría, casado y con algunos hijos pequeños, considerársele un campesino comunero más de la comunidad de Cariquima, junto a la frontera con Bolivia en la actual comuna de Colchane. Durante los años del gobierno de la Unidad Popular su comunidad (un poblado de la comunidad histórica de Cariquima) mantenía una escuela de primeras letras a cargo de un profesor (JO) marcadamente adepto al gobierno de Allende, con militancia política activa y conocida. Su fervor político y revolucionario lo llevó a explorar la posibilidad de comprar e internar armas de fuego desde Bolivia. Se apoyó para ello en el vecino, de su confianza, Don Zenón E. En 1972, con su concurso, sus contactos y conocimiento de la región boliviana cercana (Llica, departamento de Oruro) podrían lograrse esas compras. Quienes conocen del caso y él mismo en su relato señalan que un arma de puño logró internarse, y una carabina Winchester según su propio testimonio, pero nada más. Esas carabinas de repetición eran conocidas por su uso en la caza de vicuñas. Recibió a cambio algún dinero como pago. Con el golpe militar de septiembre de 1973 el profesor retornó a Iquique, con suerte más que incierta. Apresado y torturado confesó todo lo que había intentado organizar en la frontera chileno boliviana. Entre otras cosas, el nombre y las acciones de los campesinos que habían sido en algún grado partícipes de sus intentos.

Traspuestas algunas semanas, Zenón fue apresado por Carabineros en el poblado donde se encontraba realizando labores agrícolas, cercano a su comunidad, guiados por el Inspector de Distrito de aquel entonces, otro comunero. Señala no haber sido especialmente maltratado por la patrulla de carabineros. Se le encarceló y trasladó al campo de reclusión de Pisagua, acusado de tráfico e internación de armas de fuego en la frontera. Estuvo allí alrededor de dos meses. El tribunal militar lo condenó por ese hecho y por su condición de cómplice y ayudista de activistas políticos revolucionarios que pretendían obtener armas para realizar un golpe de Estado. Se le condenó a tres años de cárcel y fue trasladado a Angol, donde logró estar una semana, y luego a Lebu, donde cumplió la mayor parte de su condena. En Lebu tuvo un buen pasar. Luego de unos meses fue asignado como ayudante de cocina y poco más adelante cocinero de los gendarmes. La lejanía con sus familiares le impidió recibir cualquier visita (esposa e hijos), alimentos u otros objetos. Según sus palabras, vivió aislado.

Cumplida la condena volvió a su comunidad de origen intentando reincorporarse a las actividades campesinas de cultivo y pastoreo de animales. Según él mismo, no se habría sentido cómodo ni logrado reintegrarse a la familia después de tanto tiempo. Habría entonces decidido buscar mejor suerte en otro sitio. Se marchó a la quebrada de Chilla (inmediaciones de las minas Quebrada Blanca y Collahuasi, en la alta cordillera, en el límite entre la 
región de Tarapacá y la de Antofagasta). Por aquel entonces con actividad de pirquinero en el lavado de oro. Según otras versiones, al poco tiempo de retornar del sur de Chile se inmiscuyó con una mujer casada de su propia comunidad. El caso llegó a saberse y temiendo duras represalias de la familia del afectado, una rama de su propia familia, y de la propia comunidad, albergando incluso temores por su vida, decidió irse furtivamente en medio de la noche ${ }^{11}$. Se internó en Bolivia avanzando hacia el sur cerca de la frontera y de allí volvió a ingresar a Chile, arribando a Chilla. Permaneció cuatro años en el sector. Conoció a la que es su pareja actual en la frontera, sector de Ujina, donde en ocasiones se hacía una pequeña feria fronteriza chileno-boliviana. Ella es de nacionalidad boliviana en su origen, viuda y con hijos, de la localidad de Tawa, un área aymara en el extremo del área de extensión meridional de esa lengua. Posteriormente y tras muchos años en Chile se nacionalizó chilena. Zenón también se trasladaba ocasionalmente a poblados del otro lado de la frontera, ligadas a faenas azufreras de Bolivia, con fines de abastecimiento y comercio. En Chilla, luego de prestar alojamiento a un par de conocidos, se vio envuelto en una situación judicial compleja. Esos conocidos trasladaban en el auto colectivo que habían robado con violencia, provenientes de Iquique, el cadáver del propietario, que luego enterraron en la frontera, para de ahí vender el automóvil robado. Fue interrogado en Pozo Almonte luego de saberse que las herramientas empleadas por los asaltantes para enterrar al propietario del taxi eran de su propiedad. Estaban comprometidos en un asesinato anterior de similares características. Por tratarse de una relación circunstancial salió en libertad.

Chilla parecía no ser el mejor lugar para permanecer y hacer vida allí. Con algunos ahorros, nueva pareja y buscando mejores horizontes llegó a las comunidades del Alto Loa y a Calama, realizando distintos trabajos. Por compra pudo hacerse de algunas tierras en la localidad de Lasana, mejorarlas y practicar chacarería por ya más de dos décadas. Mantiene contacto con un hijo e hija de su anterior familia, residentes actualmente en Pozo Almonte. Se sostiene en el presente con ingresos por venta de productos agrícolas y, especialmente, la confección, intermediación y venta de artesanías.

Los apremios físicos, castigos y golpes no los recuerda tanto como otras dos formas de violencia padecida en su estadía en Pisagua. La primera fue la ausencia de alimentos, de comida, por varios días y en más de una ocasión mientras duró su encarcelamiento en ese campo de detención. Lo segundo y más intenso aun como experiencia fueron las amenazas de fusilamiento que repetidamente recibió. En Pisagua hubo fusilamientos y la desesperación cundía en él, y en otros, por la incertidumbre de si iba a ser ajusticiado o no y en qué momento esto ocurriría. Ello finalmente no sucedió. Logró más tranquilidad cuando empezó a ser procesado. Resignado, se le sentenció y se dispuso a cumplir condena en el sur del país. Aceptó los hechos imputados, lamentando su imprudencia.

\section{c) Quebrada EI Toro en la puna argentina, ecos del conflicto del Beagle}

Don Leonardo (Q.E.P.D), comunero de un ayllu de San Pedro de Atacama, se quejaba amargamente de los gendarmes argentinos cuando, en 1979 y en pleno apogeo del diferendo entre Chile y Argentina por el austral Beagle, fue apresado por ellos en la localidad de El Toro, departamento de Susques, en la puna de Jujuy, cerca de la frontera con Chile. Los recuerdos se le agolpaban especialmente cuando bebía con amigos y algo de la conversación generaba esos recuerdos. Ya enfermo nos relató detalles de los meses aciagos en que fue retenido en San Antonio de los Cobres y, más tarde, trasladado en el ferrocarril Antofagasta-Salta, desde donde estaba hasta el retén fronterizo de Carabineros de Socompa. Allí fue recibido por un oficial de Carabineros.

Como era común todavía en aquellos años, arrieros chilenos se trasladaban desde los oasis de San Pedro o comunidades precordilleranas hacia las comunidades ganaderas, atacameñas, de la Puna de Argentina. También hacia comunidades quechuas ubicadas en el extremo sur poniente de la provincia de Lípez. Y a la inversa, desde esas comunidades (Catua, Huancar, El Toro en Argentina, o Quetena en Bolivia) hasta las localidades de Toconao, San Pedro de Atacama o Socaire. Desde acá productos campesinos como chañar, frutas secas y algún producto industrial chileno. Desde allá, sogas de lana de llama, charqui y carne fresca, hoja de coca, a veces burros y mulas, pero también productos de consumo argentinos cotizados acá como jabón de lavar, aceite comestible, abarrotes en general, ollas de fierro.

En aquella ocasión viajó con otros dos compañeros, uno vecino de San Pedro de Atacama, no atacameño, más interesado en conocer que en 
trocar o hacer comercio, y otro de la localidad de Toconao. Leonardo y su amigo de Toconao viajaban con alguna frecuencia para intercambiar y comerciar productos en localidades como las indicadas. Lo hacían con apoyo de burros y mulas. La primera parte del viaje la realizaron en camión azufrero hasta el sector de Hito Cajón llevando la mercadería y cargas de viaje (aparejos de mulas, frazadas, útiles de cocina, forraje, alimentos para el viaje). Los animales los enviaron un día antes sin peso a cargo de un peón. Hasta ahí llegó el vecino de San Pedro, volviéndose en camión con el peón, aprovechando su bajada desde un yacimiento en volcanes cercanos. En unas jornadas los arrieros se encontraban ya en la quebrada de El Toro ${ }^{12}$. Se trata de una localidad en que no había controles fronterizos de aduanas o policía y donde tenían "caseros", familias del lugar con quienes llegaban, pernoctaban y con los que trocaban y comerciaban. Sabían del aumento de controles y patrullajes en la frontera con Chile producto de las tensiones políticas por el Beagle, pero desestimaron los riesgos, basados en su conocimiento del terreno (senderos de arriería), el pequeño tamaño de la localidad sin destacamento policial estable y también la expectativa de ayuda que esperaban recibir de las familias amigas si surgía algún contratiempo.

Llegaron a El Toro y se instalaron. Al día siguiente temprano apareció intempestivamente una patrulla del ejército argentino. No lograron ocultarse suficientemente y don Leonardo fue ubicado agazapado en la cabina de un pequeño camión. Su compañero trató instantes antes de huir por el campo pero una bala en una pierna lo detuvo. La mujer que los hospedaba no quiso comprometerse en defenderlos y tratar de poner las cosas en contexto. Fueron inmediatamente tratados como agentes estatales chilenos que buscaban información acerca de la presencia y actividad de las fuerzas armadas argentinas en la frontera. El ocultamiento de uno de ellos y la huida del otro parecía comprobarlo suficientemente.

De ahí en adelante las cosas se agravaron para los dos arrieros. Ambos fueron trasladados primero a Catua y luego a San Antonio de los Cobres donde se encontraban acantonadas fuerzas argentinas, y separados entre sí. No volvieron a encontrarse hasta meses más tarde, ya en Chile, luego que Leonardo fuera dejado en la frontera. Este último fue interrogado intensivamente, amenazado de muerte muchas veces, golpeado y mantenido encarcelado en condiciones muy duras. Recordaba muy nítidamente la dureza de los apremios físicos que recibió. Insistían en que confesara su relación con las fuerzas armadas de Chile y que se encontraba en Argentina realizando labores de espionaje. Trató de razonar con ellos, gimió, gritó, lloró durante las golpizas acerca de su condición de campesino interesado en bienes de consumo de la Puna y en abarrotes argentinos, nada más. En más de una ocasión quienes lo interrogaron aludieron a la situación de disputa internacional que se vivía en el Cabo de Hornos, buscando relacionarlo con labores de espionaje militar especialmente activos allá. Después de muchos días los interrogatorios cesaron pero igual lo mantuvieron encarcelado. Paulatinamente cesó la dureza del trato y se le obligó a prestar ayuda en tareas de aseo y mantenimiento en el destacamento. En una ocasión fue sorprendido observando un sector reservado de las instalaciones militares y nuevamente interrogado y golpeado. Finalmente, después de aproximadamente 4 meses se le trasladó hasta la frontera en ferrocarril y dejado allí cerca de la estación de Socompa. De ahí se le traslado a Antofagasta y fue interrogado concienzudamente por oficiales del ejército chileno. $\mathrm{Al}$ parecer su caso era conocido por el testimonio de su compañero de viaje, quien había sido devuelto con anterioridad a Chile.

Recién entonces pudo volver a su casa y retomar sus actividades campesinas. Solo a los años se atrevió nuevamente a volver a las comunidades atacameñas argentinas de la puna de Jujuy y Salta para intercambios y trajines comerciales. Le quedaba el recuerdo amargo de esos meses aciagos en que un conflicto binacional en el otro extremo de ambos países lo afectara de una manera tan dramática.

\section{Fronteras andinas, violencia estatal e indígenas}

Un capítulo especial de violencia política que afectó a indígenas se vivió en las regiones de Tacna y Arica durante y con posterioridad a la Guerra del Pacífico, hasta la definición de fronteras terrestres de 1929. Por una parte, el ejército peruano integraba soldados indígenas (quechuas y aymaras) y personal auxiliar de las provincias de Tarapacá, Arica y Tacna, también indígenas. Ellos participaron directamente de operaciones militares y muchos murieron o fueron heridos en esas contiendas. Por otra, la soberanía de estas regiones quedó pendiente 
de resolver mediante un plebiscito nunca realizado. En los 50 años de ocupación chilena de Tacna y Arica la ejecución de un plebiscito supuso intentos de los gobiernos chilenos por ganar la voluntad de sus habitantes, el traslado de personas y familias hacia esas regiones, inversiones públicas, escuelas, etc. En las áreas andinas (valles occidentales de la cordillera de los Andes) la población era mayoritariamente indígena aymara, según reconocen los documentos de la época. Una parte de ellos adhirieron pública y activamente a la causa nacional peruana y resistieron las presiones chilenas. La relación entre autoridades locales, policías y funcionarios chilenos con ese sector opositor y la población indígena en general tuvo momentos de conflicto abierto y violencia, incluyendo encarcelamiento, apremios físicos y la muerte de algunos campesinos. Son bien conocidos algunos hechos de violencia con resultados de muerte en el poblado precordillerano de Putre (para un análisis más amplio González, Maldonado y McGee, 1994; para Putre, Díaz, Ruz y Galdámez, 2013: 473-492).

Traspuesta esa etapa, a partir de inicios de la década de 1930 se constata una acción de normalización de la acción estatal en el espacio andino, lo que supone la operación regular de instituciones del Estado; por ejemplo, Inspectores como representantes locales de gobierno interior, Jueces de Paz intermediando la relación con el sistema judicial y resolviendo faltas y disputas, profesores de enseñanza de primeras letras, el control aduanero y policial de las fronteras, o funcionarios municipales que desde cabeceras urbanas visitaban anexos. Ello tiene una progresión lenta, pero ascendente, con el paso de las décadas: mejores caminos y comunicación terrestre; operación regular de ferrocarriles estatales; más escuelas funcionando normalmente; progresiva mayor presencia de funcionarios públicos en misiones oficiales; nuevas formas de organización como las Juntas de Vecinos en la década de 1960, etc. Y también una progresivamente mayor regulación policial y fiscal de fronteras, para controlar la internación de productos y mercaderías desde los países vecinos, la circulación ilegal de personas, el comercio irregular o simplemente clandestino desde Chile hacia Bolivia o Argentina. Nuevas instalaciones policiales y aduaneras y mayor dotación de personal siguió esa progresión. En este período, puede decirse, la coacción física directa, la violencia y brutalidad de agentes públicos hacia los indígenas persistió, pero sin las características del período anterior. El castigo escolar fue recurrente, el amedrentamiento policial existía, abusos y excesos también, pero solo excepcionalmente con consecuencias como las descritas en los casos presentados.

Anotemos, todavía, que el aumento de instalaciones policiales y de fuerzas armadas en las fronteras andinas que se vivió desde mediados del siglo XX en adelante no obedece solo a la recurrencia e intensificación del comercio fronterizo ilegal. Tanto o más importante que lo anterior fueron momentos de conflicto y tensiones diplomáticas entre países a propósito de situaciones de frontera (definición del límite norte con Perú; diferendo por el uso de las aguas del río Lauca con Bolivia; irrupción de patrullas militares hacia uno u otro lado de la frontera; controversia por el salar de Surire; y, en especial, a fines de la década de 1970, con prolongaciones hasta los primeros años de 1980, fuertes tensiones políticas y amenazas de conflicto armado con ocasión del centenario de la Guerra del Pacífico y las tensiones con Argentina por el Canal Beagle en el Cabo de Hornos).

Por otra parte, autoridades y funcionarios del Estado, Carabineros de Chile en particular, mantuvieron una visión altamente problemática de los indígenas del norte de Chile, según dos componentes discursivos principales. Por una parte, carencia de civilización, atrasados, incultos, "indios" en suma, que posiciona a los indígenas en una situación de gente primitiva, carentes de un progreso equivalente al de los demás habitantes del país. Por otra, la permanente atribución o sospecha de extranjeridad, de personas y comunidades que por su historia, lengua y costumbres corresponderían a bolivianos, "indios bolivianos", o peruanos. Ahora, respecto de los indígenas argentinos podría reconocérseles como "indios", pero difícilmente se podía hacer extensiva esa apelación a todos los argentinos, como sí ocurre con los bolivianos. La condición de extranjeros "en su propia tierra" fue defendida muchas veces por nacionales peruanos indígenas de la provincia de Tarapacá y lo fue especialmente en la zona de Arica y Tacna hasta la resolución de límites de 1929. Pero esa extendida percepción se mantuvo vigente por autoridades y funcionarios públicos, incluso hasta hoy. A pesar de que en la propia población indígena un sentido de pertenencia nacional chilena se fue incorporando progresivamente y con fuerza.

Por tratarse de una de las presencias estatales más regulares en las áreas altoandinas de frontera en el norte de Chile con Perú, Bolivia y Argentina, 
resulta sugerente citar al oficial de Carabineros Sergio Márquez, quien hacia mediados de la década de 1950 recorrió extensamente el altiplano de Arica en labores de supervisión de los retenes de frontera por ese entonces existentes. Refiriéndose a los pobladores del valle de Codpa, uno de los más cercanos a Arica en sus recorridos, comenta que "Codpa es un poblado de más o menos seiscientos habitantes, que han vivido con los siglos en forma primitiva, aislados de la civilización" (Márquez, 1967: 94). Si esto es válido para un valle de mestizos andinos que estaban lejos de considerarse a sí mismos como indígenas, puede imaginarse qué visión y juicios podrían merecerle los villorrios fronterizos que visitó. A propósito de la enseñanza de primeras letras que realizaban carabineros del retén de Guallatire, dice que "mantienen una escuela para enseñar a los niños las primeras letras... [evitando así] que la niñez menesterosa, de estas solitarias regiones cordilleranas, caiga en las tinieblas eternas del analfabetismo" (Márquez, 1967: 52). Pobladores primitivos, carentes de acceso a la civilización, con riesgos de permanecer en tinieblas culturales, etc., etc. Si esto es así para los habitantes del lado chileno, podemos esperar respecto de las aldeas bolivianas vecinas juicios igual o más críticos que los citados. Al respecto, el oficial Márquez es algo más contenido, pero igualmente claro en su manera de ver a los pobladores de localidades aymaras bolivianas vecinas a la frontera chilena. Esta visión de los agentes públicos acerca de los habitantes de la alta cordillera andina es de larga data y tiene continuidades hasta el presente.

Durante el período autoritario del gobierno de Pinochet, una mayor vigencia de la acción estatal se caracteriza por una presencia policial y militar notoria en el espacio andino, la anulación de derechos civiles y políticos, control y regulación social e intervención de las organizaciones de base, todo ello apoyado en una retórica de restauración del orden público y un manifiesto nacionalismo. Algunos dirigentes indígenas de izquierda se escondieron o emigraron de sus comunidades, otros debieron tolerar vigilancia y amenazas, unos cuantos fueron condenados o exiliados por su conexión con el gobierno socialista de Salvador Allende y se sabe de "desaparecidos". Fueron conocidos también actos de violencia arbitraria sin ajustarse a protocolo policial alguno. Son características del período una mayor presencia de agentes públicos, el funcionamiento continuo de establecimientos escolares, mayor diligencia en sostener y ampliar la conectividad terrestre, redes de radiocomunicación, campañas sociales y sanitarias a cargo de las fuerzas armadas, activación de celebraciones y ritualidad política nacionalista.

Al respecto, tres cursos de acción son importantes de hacer notar. Primero, el plan de escuelas de concentración fronteriza, dirigido al reforzamiento de la infraestructura y los servicios escolares en zonas extremas del país (extremos y márgenes geográficos, en prácticamente todos los casos asociados a fronteras políticas). Segundo, la municipalización del espacio andino. A principios de la década de 1980 se crean municipios en todas las zonas interiores; previamente constituían anexos distantes de municipios cuyas cabeceras se encontraban en la costa o el desierto intermedio. Además de acercar el Estado a los pobladores andinos, esta importante reforma fue también un eficiente dispositivo de control político y social de la población indígena. Como tercer aspecto resalta la impronta nacionalista de la acción del gobierno militar. Por ejemplo, el reforzamiento de un sentido de "chilenidad" (escuela pública que reforzaba valores patrios, rituales públicos celebratorios de la nacionalidad, inculcación nacionalista en el actuar del personal de la policía y las fuerzas armadas). La puesta en funciones de los municipios y la dependencia a ellos de las escuelas públicas otorgó el cuadro institucional perfecto para estas labores de inculcación, acción ritual y sentido nacional de la acción estatal. Pero también lo hace la insistencia en la demarcación de los que son "chilenos" respecto de los "peruanos" o "bolivianos", indígenas y más atrasados e, incluso, menos civilizados que los de "este lado". También fueron manifiestas, especialmente en la zona aymara altiplánica, las dudas acerca de la nacionalidad de estos indígenas ${ }^{13}$ y su efectiva lealtad a Chile ${ }^{14}$.

\section{Conclusiones}

El extremo temporal aquí considerado, desde el término de la Guerra del Pacífico hasta la definición de la soberanía sobre Tacna y Arica 1883-1929, posee características propias en lo que se refiere a la violencia y coacción física de agentes estatales hacia indígenas y ha sido razonablemente estudiado por los autores que citáramos más arriba. Insistamos, no obstante, en una clave de interpretación de esa violencia en tanto fue 
ejercida hacia "otros" extranjeros, específicamente peruanos. La condición y atributos indígenas de parte de esa población se definen mejor como un atributo o propiedad de esos otros "extranjeros" y no como como una definición de sujeto contra el que se ejecuta violencia. Y, por tanto, la "chilenización" es un asunto de incorporación compulsiva y por momentos violenta de extranjeros y no de asimilación étnica, aunque en los hechos y visto con el prisma de las visiones de sociedad actuales ello habría ocurrido por defecto (con más amplitud en Gundermann, 2018: 94-97).

Con posterioridad a esas décadas, las relaciones entre agentes públicos e indígenas de la cordillera andina nortina, al no estar ya mediada por un conflicto político territorial, por lo común no tuvieron la dureza que hicimos mención para la zona de Arica y Parinacota en el medio siglo precedente. La violencia verbal de unos a otros fue común, por policías y profesores de escuelas públicas en particular, según testimonios recogidos. Hasta muy recientemente, el castigo físico fue usual en la relación escolar por parte de profesores de primeras letras; práctica normalmente consentida por los padres como un recurso de la educación mientras se mantuviera dentro de límites, sin lesiones visibles. Hechos de alguna violencia se suscitaron a veces por parte de policías cuando sus requerimientos no fueron atendidos; por ejemplo, para la obtención de alimentos y forrajes en patrullajes por la cordillera. Por la parte indígena, lo más frecuente fue la diligente ayuda que autoridades indígenas y comuneros brindaban a estos funcionarios, pero también trataron de evitar contacto con ellos, huir y esconderse, en especial las mujeres y niños. Coacción física más extrema emergió en circunstancias particulares, con grados que van desde golpizas, apremios físicos y asesinato (cuando las cosas se "fueron de las manos"). Las circunstancias en que se produjeron los hechos más graves serían varias. Primero, la persecución y captura de fugitivos indígenas sospechosos de cometer delitos graves o personas indígenas que los tribunales exigían comparecencia. El primer caso presentado trata de la búsqueda de un fugitivo de la justicia por Carabineros que terminó en la muerte de un campesino que lo encubría. El segundo, por internación de armas de fuego desde Bolivia, hecho que se conoció con la represión política que siguió al golpe militar de 1973. El tercer caso presentado es el de un par de arrieros atacameños chilenos sorprendidos ilegalmente en la puna argentina y a quienes se atribuyó actividades de espionaje. Pero quizá lo más común es la violencia durante la comisión de delitos reales o presuntos en flagrancia. En particular, con ocasión de sorprender contrabando fronterizo e internación ilegal de mercaderías prohibidas, o animales en pie; a veces, conectado con reacción activa de afectados ante decomisos, no colaboración por parte de aprehendidos o intentos de fuga que precipitaba reacciones de la policía (o de integrantes del ejército como en el tercer caso).

Considerada ahora la violencia de agentes estatales (policías, miembros de las fuerzas armadas o personal aduanero) de los países vecinos con indígenas provenientes de territorios bajo dominio chileno, el panorama cambia bastante. Desde el lado boliviano, la internación ilegal de indígenas chilenos no suscitó o suscita por lo general mayores problemas, debido al amparo prestado por las contrapartes de negocios y trajines, a la práctica común de entregar algún dinero o especies a funcionarios para evitar que los controles, cuando se producían, tuvieran mayores consecuencias. Conocemos, no obstante, de decomisos y detenciones momentáneas. En la frontera andina con Perú, el actuar de los agentes estatales de frontera peruanos ha sido más diligente y efectivo, pero al mismo tiempo entendiendo que el intercambio y pequeño comercio campesino es una práctica antigua, con alcance limitado y que no ocasiona mayor perjuicio fiscal. Una actitud similar se conocía en la Puna de Atacama por parte de Gendarmería Argentina, además de su limitada presencia en caseríos y localidades pequeñas, precisamente donde se llevaba a efecto con mayor frecuencia el intercambio de bienes y transacciones de mercado.

A los integrantes de pueblos indígenas andinos, nacionales o de zonas fronterizas de los países vecinos se les apreciaba en Chile como carentes de civilización, primitivos y atrasados; es decir, "indios". A lo que se suma la percepción de extranjeros, de ajenos a la nacionalidad. Su inverso quedaba representado por los mismos agentes estatales (autoridades, policías, integrantes de las fuerzas armadas, profesores de escuelas, funcionarios en general), civilizados y propiamente chilenos. Los agentes del Estado fueron consistentes inculcando esa visión y, con ella, sus funciones e investiduras, imponiéndose sobre las personas y grupos indígenas con las que trataban. Especialmente en las áreas 
fronterizas altoandinas, más que en los valles y oasis occidentales donde primaba el castellano, las comunidades aymaras de Arica y Tarapacá y la población quechua (del sector Alto Loa u Ollagüe) hasta la década de 1960 fueron mayoritariamente monolingües de lenguas nativas o con conocimientos limitados del castellano. Las naturales dificultades de comunicación con policías, profesores y funcionarios monolingües castellanos acentuaban la distancia social y el sentido de superioridad de estos agentes públicos, así como la retracción y el temor indígena ante ellos. El trato de unos a otros fue por muchas décadas, entonces, marcado por la distancia social, atribución de superioridad y autoritario. Por el lado indígena, evitación, temor y actitudes sumisas como estrategia defensiva. Los pobladores andinos podían considerarse "indios" en el altiplano de Arica, Iquique o las comunidades de la cordillera de Antofagasta, respecto de ello, la acción de las instituciones del Estado permitiría un giro hacia un mayor progreso, civilización e integración de estos connacionales olvidados o poco atendidos. Es decir, podían dejar de ser "indios" o ser menos "indios". Envolvía entonces la promesa de una emancipación de la condición de "indio" que, por lo demás, la gran mayoría de ellos suscribía de manera acrítica.

Durante el gobierno autoritario entre 1973 y 1989 se implementaron diversas medidas de soberanía y control de fronteras, en particular en áreas extremas y de alta montaña del país: desarrollo de comunicaciones y caminos, municipalización (creación de municipios, instalación de servicios del Estado y dotación de funcionarios públicos estables a principios de la década de 1980), un programa de Escuelas de Concentración Fronteriza, destacamentos militares de montaña y mayor presencia de fuerzas armadas, aumento de dotaciones policiales y mejoras en sus instalaciones y equipamiento. De esta manera, la dictadura militar intensifica presencia estatal y control policial en las fronteras del norte del país. Todo ello bajo los términos de una visión geopolítica del territorio y la soberanía nacional. Esta progresiva mayor presencia y actividad estatal, policial y militar en las zonas indígenas de frontera aumentó las posibilidades de violencia y, a veces, también la muerte de indígenas. Con el golpe militar dirigentes campesinos indígenas adscritos a partidos de izquierda o proclives al gobierno de Salvador Allende fueron amenazados, perseguidos, en algunos casos encarcelados y torturados o al menos maltratados físicamente. Las amenazas de fusilamiento fueron los momentos psicológicamente más duros que padecieron, según uno de los testimonios conseguidos. Algunas personas con apellidos indígenas fueron asesinadas sumariamente en los meses siguientes al golpe militar, pero no en tanto como dirigentes campesinos, sino como obreros o dirigentes obreros de izquierda que laboraban en centros mineros, integraban sindicatos en centros fabriles urbanos y eran activistas de izquierda. Se conoce también de un par de casos de aymaras que fueron muertos en el centro de detención de Pisagua por su participación en el tráfico de drogas, pero no por ser dirigentes sociales indígenas o campesinos.

Traspuesto los primeros tiempos, las persecuciones se calmaron, pero no la presencia militar y el control policial en la cordillera andina y la frontera con Perú, Bolivia y Argentina. Los testimonios señalan inequívocamente un aumento del autoritarismo, abusos, violencia verbal y actos de coacción física hacia indígenas. Sus protagonistas principales fueron policías, destacamentos militares y funcionarios del Estado. Una extendida percepción de impunidad por sus actos ayudó a que actos arbitrarios y violentos fueran frecuentes. En contadas ocasiones se produjeron reclamos de manera individual o colectiva con consecuencias favorables para los indígenas.

El período postretorno a la democracia en Chile (1990 - ) no terminó con la violencia de agentes públicos a indígenas. Ahora se asoció directamente al control por contrabando de mercaderías, internación de animales y, sobre todo, transporte y tráfico de drogas en la frontera, desde Bolivia y Perú a Chile. Es también un período con más garantías para víctimas de apremios físicos y violencia a indígenas. Es también un período de emergencia de organizaciones que elaboran y promueven demandas étnicas en el norte del país; entre otras, aquellas referidas a las formas de acción y violencia de agentes del Estado.

\section{Agradecimientos}

El presente artículo es el resultado del trabajo conjunto de los autores en el marco del proyecto de investigación Fondecyt Regular No 1141077 "Estado y violencia hacia los pueblos aymara, atacameño y mapuche (1883-1990)" y del proyecto Fondecyt Regular N ${ }^{\circ} 1150573$ "Las relaciones interétnicas en Chile, su diversidad regional y cambios recientes", 
ambos del Fondo Nacional de Desarrollo Científico y Tecnológico (Fondecyt-Conicyt) de Chile. Agradecemos a esta agencia científica su generoso apoyo, lo mismo que observaciones, comentarios y críticas de colegas a este texto.

\section{Referencias Citadas}

Castro, Luis

2016 "Cariquimas, Islugas y Llicas: la frontera chilenoboliviana de Tarapacá y las disputas interétnicas por los recursos productivos de altura, 1883-1931”. En González, Sergio, Cristian Ovando e Ingrid Breton (Edits.). Del hito a la apacheta. Bolivia-Chile: otra lectura de cien años de historia transfronteriza (1904-2004), pp. 113-144. Universidad Arturo Prat, RIL Editores, Santiago.

Díaz, Alberto

2006 "Aymaras, peruanos y chilenos en los andes ariqueños: resistencia y conflicto frente a la chilenización del norte de Chile". Revista de la Asociación de Antropólogos Iberoamericanos en Red, vol. 2, No 1: 275-289.

Díaz, Alberto y Rodrigo Ruz

2009 "Estado, escuela chilena y población andina en la ex Subdelegación de Putre: acciones y reacciones durante el período postguerra del Pacífico (1883-1929)". Polis, vol. 8, $\mathrm{N}^{\circ}$ 24: 311-340.

Díaz, Alberto; Rodrigo Ruz y Carlos Mondaca

2004 "La administración chilena entre los aymaras: resistencia y conflicto en los Andes de Arica (1901-1926)". Anthropológica $\mathrm{N}^{\mathrm{o}}$ 22: 215-235.

Díaz, Alberto, Rodrigo Ruz y Luis Galdamez

2013 "En los intersticios de la chilenidad: Antonio Mollo y las identidades en conflicto en los Andes. Putre, 1900-1926". Chungara, Revista de Antropología Chilena, vol. 45, No 3 : 473-492.

Garcés, Alejandro y Marcelo Maureira

2018 "De familia a organización étnica: redes para una espacialidad transfronteriza en la Puna de Atacama". Revista Chilena de Antropología No 37: 230-248.

González, Héctor

1997 "Economía y uso del espacio en la sociedad aymara actual". En Actas Segundo Congreso Chileno de Antropología, Tomo 2, pp. 567-579, Santiago.

González, Héctor

1996 Características de la migración campo ciudad entre los aymaras del norte de Chile. Documento de Trabajo, Corporación Norte Grande, Arica.

González, Héctor y Sergio González

2018 "Ancomarca, la comunidad escindida. La frontera entre Perú, Chile y los aymaras del tripartito". Aldea Mundo vol. 23, $\mathrm{N}^{\circ}$ 45: 7-22.

González, Sergio

1991 Hombres y mujeres de la pampa: Tarapacá en el ciclo del salitre. Ediciones especiales Camanchaca, Taller de Estudios Regionales, Iquique.

González, Sergio

2002 Chilenizando a Tunupa. La escuela pública en el Tarapacá Andino (1880-1990). DIBAM, UNAP, CIHDBA, Santiago.
González, Sergio; Carlos Maldonado y Sandra Mc Gee 1994 "Las ligas patrióticas: un caso de nacionalismo, xenofobia y lucha social en Chile", en Canadian Review of Studies in Nationalism, vol. XXI, Nº 12.

Gundermann, Hans

1986 "Comunidades ganaderas, mercado y diferenciación interna”. Chungara, 16-17: 233-250, Universidad de Tarapacá, Arica.

Gundermann, Hans

2001 Comunidad, sociedad andina y procesos socio-históricos en el norte de Chile. Tesis doctoral, COLMEX, México D.F.

Gundermann, Hans

2018 "Los pueblos originarios del norte de Chile y el Estado". Diálogo Andino No 55: 93-109.

Gundermann, Hans; Jorge Iván Vergara y Alberto Díaz 2011 "Historia moderna de una lengua originaria: el jaqiaru en Chile. RLA Revista de Lingüística Teórica y Aplicada, vol. 49, $\mathrm{N}^{\circ}$ 1: 69-108.

Márquez, Sergio

1967 Patrullajes en el altiplano chileno. Editorial Orbe, Santiago.

Molina, Raúl

2017 "En la huella está el peligro". Arrierías de puna y desierto. Qillqa Ediciones, Serie Tesis. Instituto de Arqueología y Antropología (IAA), Universidad Católica del Norte, San Pedro de Atacama.

Provoste, Patricia

1977 Antecedentes socio-económicos para el desarrollo del sector de Isluga, Centro Isluga de Investigaciones Andinas, Universidad del Norte, Iquique.

Richard, Nicolás; Jorge Moraga y Adrián Saavedra 2016 "El camión en la Puna de Atacama (1930-1980). Mecánica, espacio y saberes en torno a un objeto técnico liminal”. Estudios Atacameños. Arqueología y Antropología Surandinas $\mathrm{N}^{\circ}$ 52: 89-111.

Riviérè, Gilles, 1979. "Intercambio y reciprocidad en Carangas". Antropología, vol. I, 1: 85-114, La Paz, Bolivia.

Riviérè, Gilles

1982 Sabaya: Structures socio-economiques et representations symboliques dans le Carangas-Bolivie, Tesis Doctorado, École des Hautes Etudes en Sciences Sociales, París, Francia.

Tudela, Patricio

1992 Transformación religiosa y desintegración de la comunidad aymara tradicional en el norte de Chile. Tesis Doctoral. Holog Verlag, Bonn, Alemania.

Tudela, Patricio

2002 El estado y la sociedad chilena ante los Aymaras de Tarapacá(1 ra. Región de Chile): factores y consecuencias de su integración entre 1930-1973. Documento de Trabajo, Comisión de Verdad Histórica y Nuevo Trato, Santiago. 


\section{Notas}

1 La excepción correspondió a Tacna y Arica, donde se hicieron esfuerzos por trasladar a ciudadanos chilenos, debido a la particular situación política y diplomática que hasta 1929 vivió esa región.

2 Por nuestra parte, resumimos estos hechos diciendo que a los agentes de la administración, los funcionarios judiciales, la policía y fuerzas armadas, los docentes de las escuelas e, incluso, el clero chileno desplegado en las regiones anexadas se impuso la tarea de difundir e imponer las virtudes del Estado chileno, basado en la imagen de la condición organizada y eficaz del Estado, la unidad y homogeneidad de su población, el mayor progreso y civilización de su sociedad, incluso la superioridad moral de sus autoridades, todo ello les otorgaba un sentido de supremacía. Por contraste, los indígenas andinos se les apreciaba en el extremo más alejado de esos valores de progreso y civilización (Gundermann, 2018: 96).

3 En la década de los años de 1930, o incluso antes, algunos comerciantes foráneos, chilenos o de origen europeo (español o croata), instalaron almacenes en algunos poblados precordilleranos, como Camiña, Chiapa, Chusmiza o Sibaya en el área de Tarapacá (Gundermann, 1986). Aunque controlaron el comercio y el abastecimiento de la población local, su mayor interés estaba centrado en el comercio fronterizo entre Bolivia y Chile, en un contexto de clandestinidad o ilegalidad. Enviaban volúmenes importantes de telas, cigarrillos, artefactos eléctricos, herramientas, vinos y licores e importaban productos de las comunidades fronterizas, como lana, fibra de camélido, pero también alcohol de caña y hojas de coca, que consumían en gran cantidad los obreros de los centros extractivos, de origen indígena, bolivianos e, incluso, chilenos provenientes del norte chico o de la zona centro sur. Los puntos en que se ubicaron estos almacenes eran estratégicos para el comercio internacional. Se trataba de sitios de acopio y despacho que permitían articular el término del transporte motorizado, hacia y desde Iquique y la Pampa, y el transporte animal por la alta cordillera hacia la frontera. Se trataba de verdaderas cabezas de playa del comercio internacional, ubicadas en distintos puntos del sector precordillerano donde terminaban los caminos interiores, que se encadenaban hacia el interior por medio de los propios aborígenes que oficiaban de arrieros para el transporte de estas mercancías. La mayoría de estos arrieros eran pastores de las comunidades del altiplano, que contaban con animales cargueros (burros, mulas y llamas machos) suficientes para alquilar y residían en las proximidades de los sitios de entrega y recepción junto a la frontera: “... de aquí no más de Chusmiza, a Chiapa, ahí no más dentrábamos nosotros... de Chusmiza se llevaban... pa' la oficina tiraban mucha coca, pa' los pampinos esos que daba el caliche... en ese camino de aguas minerales, ahí adentro metían, como agua mineral no más llevaba, he visto así... era firme comerciante ahí, un gringo que había, con un matrimonio, no sé, de Yugoslavia parece que era, se había arrancado de guerra, pero vivaracho el gringo, pa' tirar a pata es como perro, largaba no más. Hasta ahí no más llegaban los contrabandos, porque antes llevamos alcohol, coca... Nosotros claro, poníamos llamos, entonces fletes ganábamos, ve, él compraba carga y de aquí los preparamos, entonces en el camino íbamos viendo bien, si había carabineros o no había carabineros. Llegábamos a Chusmiza, listo, de allá veníamos con carga de harina o licores, vinos Santa Rita o champaña, Cinzano, traíamos eso; tres día acá, tres días allá, seis días y dos días aquí, ocho días. [...] Ya del sesenta pa'rriba ya teníamos el camino carretero ya, ya ahí terminó el lomo de animales ya..." (M.G, arriero, aymara, comuna de Colchane).

4 (Mi marido) "... casi él siempre ha trabajao en comercio... casi nunca él ha trabajao así como obrero. Él trabajaba más que nunca ha trabajaba con la Zofri, esa época abrió la zona franca, llegó a Iquique y ahí empezó a trabajar él. Nos convenía estar allá, porque allá vendía y ahí mismo teníamos nuestra casa, todo. Ahí conocí el dólar, ahí vendía en dólares (se ríe). Yo no conocía dólar, primera vez que agarre dólar de ganao. Un caballero vino a comprar gana'o con dólares, era de Pozo y después a él le pagó en dólar poh, tenía dólar y con eso se fue a la Zofri. Pa'la frontera, ahí lo vendía, así trabaja, todos los días. Por el trabajo de mi esposo, siempre había trabajao, le ha ido bien, siempre le ha ido bien en el negocio ... [C.C., mujer aymara adulta, comuna de Colchane].

5 "En el caso de Allende, ahí sí que mucha gente tuvieron la oportunidad de comprarse cosas, las cosas eran más baratas ahí, recuerdo que eran harto barata las cosas. Y de repente empezó a escasear el asunto, así que no había manera de comprar, de dónde, mercadería. No era libre así como se compraba en cualquier parte, pero plata sobraba, había cualquier cantidad de plata. Cualquier jovenzuelo tenía plata, pero no había de dónde comprar puh. Recuerdo yo los primeros años del gobierno de Allende, ese tiempo hubo un movimiento de negocios, de compra, de venta. Ahí mucha gente ganaron plata, pero de nada le ha servido también. Ganaron plata, porque había un mercado negro, la gente se convirtió en un grupo de comerciante. Pero después se fue escaseando, a la final se convirtió en un terrible contrabando de artículos. Los bolivianos compraban cualquier cantidad de cosas chilenas, porque era sumamente barato" [E.CH., hombre, aymara, comuna de Colchane].

6 "Ahora sí con la vida que está caro en Chile, ya nosotros de aquí de la feria consumimos, mercadería, arroz, azúcar, harina, todo. Allá está a ocho lucas el saco de harina y aquí está a ocho lucas también y de allá pa' traer hay que pagar dos lucas más, diez lucas sale, entonces más vale comprarse acá... Aquí el fideo está barato, fideo en granel y azúcar también está barato, harina también está barato, esa la primera que también consumimos nosotros, ve. Acá el paquete de Omo está a mil doscientos creo, el de dos kilos y aquí está a mil cien, mil pesos, su bolsa grande; así que más vale comprarse acá antes de traer de Iquique, porque aquí en Chile, la feria de Chile lo único la feria que hace con pura ropa americana, eso es lo que vende, porque otra cosa ya no conviene... Fruta viene, uva más bien eso, uva, manzana esas dos cosas [...] Toca que se echa a perder acá en Chile, toca que sea caro o no haiga ya nada o bien en Bolivia y acá también llega todo, aquí en la frontera ya viven de aquí en la frontera chilena también, así poh. [M.G., hombre aymara, adulto].

7 Una obra de consulta obligada para el intercambio y vínculos mercantiles entre personas, familias y comunidades 
atacameñas y coyas en Chile y Argentina es el libro de Molina (2017).

8 Se conoce también de actividades de aprovisionamiento de centros mineros o urbanos (como la llareta para Chuquicamata y Calama o la queñoa para Arica) usando camiones y ferrocarril (Arica-La Paz y Antofagasta-Bolivia). Para una presentación y discusión de la persistencia de normas colectivas consuetudinarias referentes al funcionamiento de la institucionalidad comunitaria, normas que regulaban la condición de comunero, la exclusión de las mujeres a ls propiedad ganadera y formas de acción y castigo colectivo, tomando como caso principal la comunidad aymara de Isluga durante el siglo XX véase Gundermann (2001). La existencia de estas potestades colectivas no obedecen solo a su persistencia en las prácticas sociales de la sociedad indígena, sino también a la relativa ausencia o poca presencia efectiva del Estado, y a la incapacidad derivada de dar cumplimiento a las leyes vigentes. Con frecuencia, delegados estatales como los Inspectores de Distrito y Jueces de Paz, aymaras todos ellos, combinaron criterios y cursos de acción de la legislación nacional, con criterios y normas locales para dirimir asuntos contenciosos matrimoniales, familiares o comunitarios.

10 La búsqueda de noticias en los periódicos provinciales de la época no arrojó hallazgos. Tampoco en el Archivo Judicial de Pozo Almonte, previamente en Huara y antes de eso en Pisagua. Tampoco encontramos noticias de este asunto y del que ahora relatamos en el Archivo de la Intendencia de Tarapacá.
11 En los años que ocurrió lo que aquí se relata todavía comunidades como esta consideraban tener el derecho de confirmar o quitar el derecho a la condición de comunero y por tanto a la pertenencia y membresía colectiva, la capacidad de exiliar y la de imponer castigos, llegado el caso, a alguno de sus integrantes. Estas potestades consuetudinarias no siempre se activaron, se mantuvieron en un rango bajo de coacción y no escalaron, o bien no llegaron al conocimiento de la justicia ordinaria o las autoridades de gobierno interior. Como sea el caso, tenían efectividad a juzgar por el autoexilio implicado en este caso.

12 Para una descripción de la ruta de arriería que conecta comunidades del Salar de Atacama con la localidad de El Toro, véase Garcés y Maureira, 2018: 238.

13 Se comentaba, por ejemplo, que podían fácilmente asimilarse con los indígenas bolivianos, que la lengua que mantenían los emparentaba con ellos, lo mismo que sus costumbres, celebraciones y rituales colectivos, actividades y hábitos familiares. Que muchos tenían también documentos bolivianos, o peruanos, o argentinos, doble nacionalidad y parientes y vinculaciones allá, etcétera.

14 De allí que el estado o condición de indígenas de estos "pobladores", como les llamaba la prensa regional, resultara problemático y ambiguo: por su carencia de progreso y civilización y por su proximidad física (frontera) y cultural (lengua, instituciones comunitarias, religiosidad) con los países vecinos representados como diferentes y hostiles a Chile. Soberanía e integración serán las claves políticas de la acción estatal autoritaria del período. 
